\title{
7
}

\section{Booms, Busts and the Governance of the Eurozone}

\author{
Paul De Grauwe and Yuemei Ji
}

\subsection{INTRODUCTION}

Since the eruption of the sovereign debt crisis in the Eurozone, substantial efforts have been made to create a new form of governance for the Eurozone that will make the Monetary Union more robust in absorbing future economic and financial shocks. Much of the drive to adapt the governance of the Eurozone has been influenced by the traditional theory of optimal currency areas (OCA), which stresses the need for flexibility in product and labour markets. As a result, the Eurozone countries have been pushed towards structural reforms that aim to reduce the structural rigidities in product and labour markets, in the hope that this would lead to a more resilient monetary union capable of withstanding future asymmetric shocks.

Figure 7.1, which presents the OECD product market legislation index, shows that the Eurozone countries have introduced structural reforms at a faster pace than the rest of the OECD countries. Figure 7.2, which presents the OECD index of employment protection, shows how the Eurozone has significantly reduced its tight employment protection, especially since the sovereign debt crisis in 2010. It is interesting to note that since the early 1990 s the non-Eurozone OECD countries have followed a reverse trend of increasing employment protection. In this chapter, we ask whether this movement towards structural reform as part of the push for new governance is going in the right direction. We will argue that this is not the case. The main reason is that the nature of the shocks that have hit the Eurozone does not correspond to the pattern of asymmetric shocks that has been identified by the OCA theory to require more flexibility. We will argue that what is needed in the Eurozone

We gratefully acknowledge the comments and suggestions from Daniel Gros, André Sapir, Frank Vandenbroucke. 


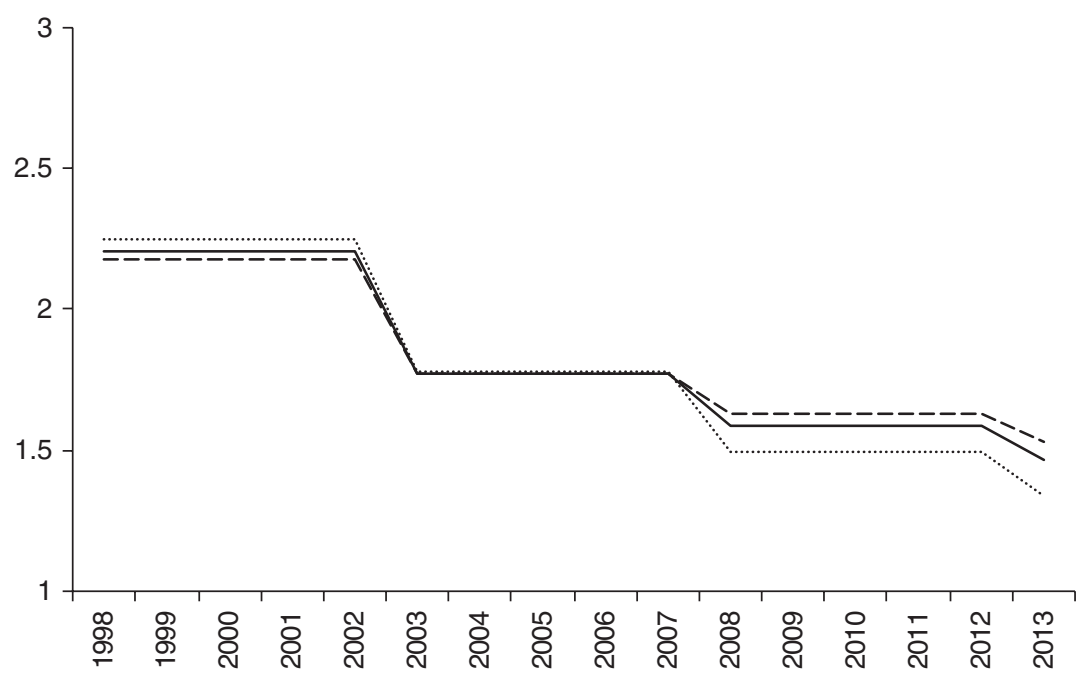

\section{- OECD …….......Eurozone ---- Non-Eurozone}

FIGURE 7.1: Product market legislation index.

Source: OECD.

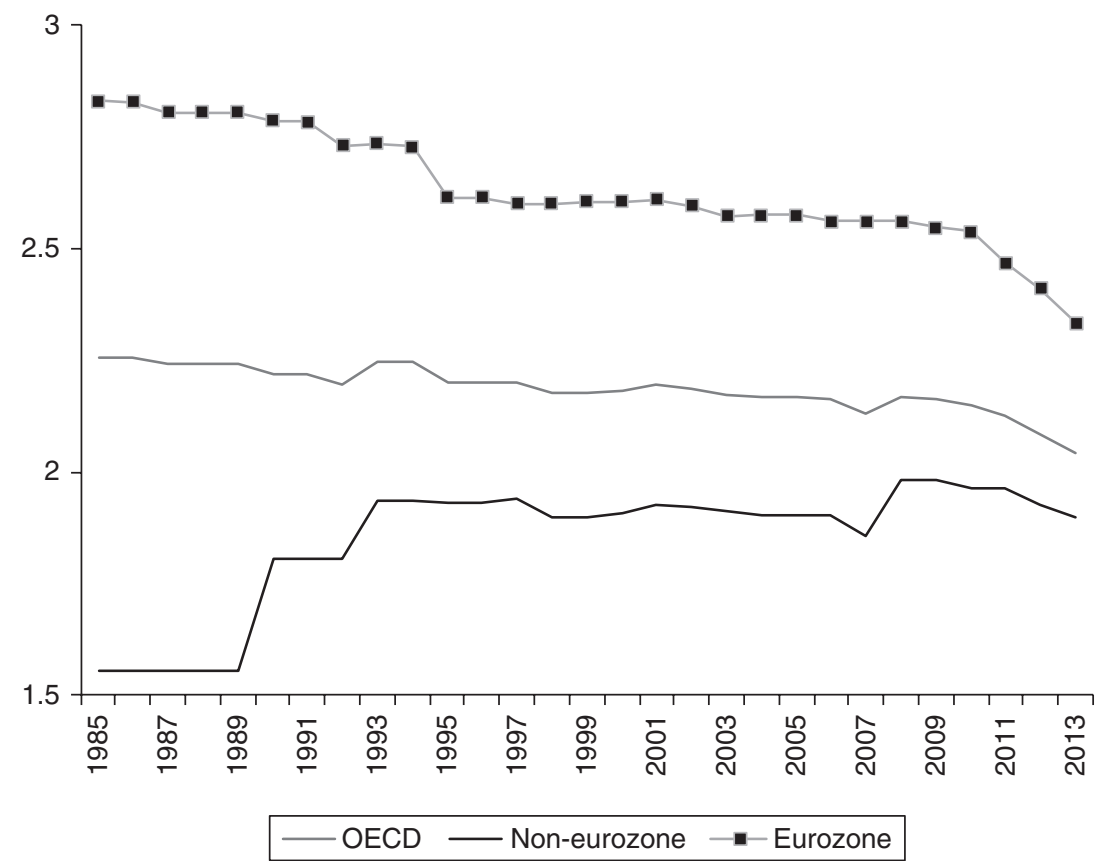

FIGURE 7.2: Employment protection legislation index.

Source: OECD. 


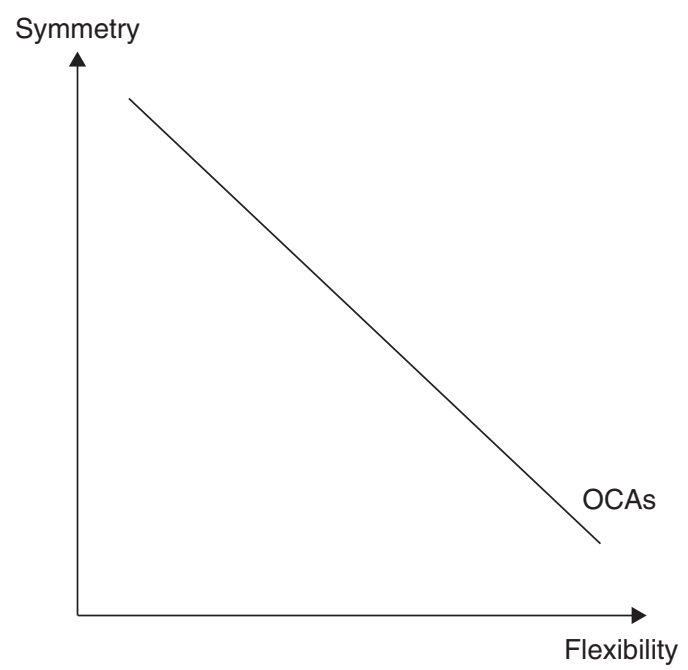

FIGURE 7.3: OCA theory trade-off between symmetry and flexibility.

is not more structural reforms but a better mechanism capable of dealing with the classical boom and bust dynamics that are inherent to capitalism.

Hyman Minsky's classic analysis of booms and busts in capitalist systems stresses the need to stabilise using government mechanisms. ${ }^{1}$ We will ask whether the Eurozone, which has moved towards more flexibility, provides for this stabilising mechanism. In Sections 7.2 and 7.3, we analyse what the OCA theory has to say about the need for flexibility and stabilisation in the face of asymmetric shocks. In Sections 7.4 and 7.5 we analyse empirically the nature of these shocks in the Eurozone and in Sections 7.6 and 7.7 we study what this evidence might means for the governance of the Eurozone. We conclude in Section 7.8.

\subsection{STANDARD OCA THEORY AND THE GOVERNANCE OF THE EUROZONE}

The theory of OCA has created a set of ideas that has a significant influence on the governance of the Eurozone and on views about how this governance should be strengthened in the future. The best way to make this clear is to present the core of the OCA theory, using a well-known graphical representation of this theory. ${ }^{2}$ This is done in Figure $7 \cdot 3$. On the horizontal axis we set

1 H. Minsky, Stabilizing an Unstable Economy (Yale University Press, 1986).

$=$ See P. De Grauwe, Economics of Monetary Union (Oxford University Press, 11th edn, 2016). 
out the degree of flexibility in the labour and goods markets. This measures the degree to which wages and prices adjust freely to shocks and the degree to which workers are mobile. We assume that these different dimensions of flexibility can be represented by one index. On the vertical axis we set out the degree of symmetry between countries, that is the degree of co-movement (correlation) of macroeconomic variables such as output and employment. Thus, when there are a lot of asymmetric shocks we move downwards along the vertical axis. By contrast, when shocks become less asymmetric we move upwards along the vertical axis. The downward sloping OCA line represents the trade-off between symmetry and flexibility. Hence, when the degree of symmetry declines (there are more asymmetric shocks) countries in a monetary union need more flexibility to deal with these shocks. The OCA-line separates the space into two zones. The OCA-zone above the OCA-line contains the collection of points at which symmetry and flexibility are high enough to guarantee that the benefits of the monetary union exceed the costs. The points below the OCA-line are the points at which symmetry and flexibility are too low, meaning that countries located in that zone will find that the costs of the monetary union exceed the benefits. The OCA-line that separates the two zones can therefore also be defined as the collection of points for which the benefits and the costs of the monetary union are equal.

This theory has been very influential for the governance of the Eurozone and continues to be so. It is at the core of the policy prescriptions that call for structural reforms so as to make the labour and goods markets more flexible. In fact, since the start of the sovereign debt crisis in 2010 member countries have been pressured by the European Commission to introduce a whole set of structural reforms. The member countries that turned to the Eurozone for financial support (Greece, Ireland, and Portugal) were given this support conditional on introducing a series of structural reforms that would make labour and goods markets more flexible. The underlying rationale was the OCA theory that stresses the need for flexibility to deal with asymmetric shocks in a monetary union.

One of the underlying assumptions of this theory and its prescription for flexibility is that the asymmetric shocks are permanent. When shocks are permanent, such as a change in preferences that leads consumers in one country to buy more of the foreign than of the domestic good, or a productivity increase in one but not in another country, then there is really no other way in a monetary union to deal with such a shock other than changing relative prices (wages or product prices) or by a movement of labour and capital. Things are very different, however, when shocks are temporary. In that case, it can be argued that flexibility is not necessary. In fact it can even be harmful. Take the case of business-cycle movements. When these are asymmetric, in other 
words when they are not synchronised, it makes little sense to adjust by relative price changes and/or by movements of labour and capital. Flexibility may in fact exacerbate the business-cycle movements and its asymmetry. For example, if country A experiences a recession and country B a boom the movement of labour from A to B is likely to exacerbate the recession in country A and the boom in country B. Or take flexibility of wages. If during the recession country A is forced to reduce wages, the immediate effect of the wage cuts will be a decline in aggregate demand, which will make the recession in country A more severe. From the preceding analysis it follows that temporary shocks, such as business-cycle movements, should be dealt with differently: by stabilisation efforts that smooth consumption over time.

However, the OCA theory that focuses on the trade-off between flexibility and symmetry was developed on the assumption that asymmetric shocks are permanent. These shocks are also typically exogenous, like meteor impacts. There is nothing one can do about these. One is forced to adjust by making the system more flexible. Business-cycle shocks, by contrast, can be said to be endogenous. They are the result of endogenous movements in optimism and pessimism that lead to booms and busts. These movements have been endemic in capitalism and will continue to do their work also in a monetary union. They have been described by Minsky and Kindleberger. 3 To the extent that these movements are not synchronised, they do not call for more flexibility; rather they call for insurance mechanisms that allow countries experiencing a downturn to be compensated by countries that experience a boom, in such a way that when the fortunes of countries are reversed the transfers are reversed. It has long been recognised that such an insurance mechanism requires some form of budgetary union. Thus, endogenous and asymmetric business-cycle movements call for very different institutions in the union from the permanent and exogenous shocks that have been at the core of the OCA analysis.

\subsection{GOVERNANCE OF A MONETARY UNION IN THE FACE OF TEMPORARY SHOCKS}

In this section we consider what the nature of the institutions of a monetary union should be when the shocks are endogenous, temporary, and asymmetric. We will focus on business-cycle movements that are driven by 'animal spirits', that is to say, movements of optimism and pessimism that lead to booms

3 Minsky, n. 1 in this chapter; C. Kindleberger, Manias, Panics and Crashes. A History of Financial Crises (John Wiley \& Sons, $4^{\text {th }}$ edition, 2001). 


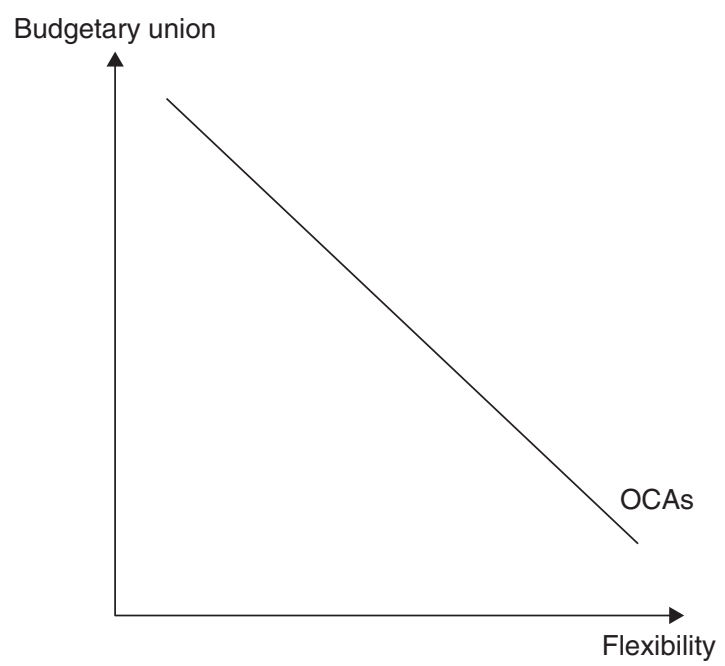

FIGURE 7.4: Trade-off between budgetary union and flexibility.

during periods of optimism and recessions during periods of pessimism. In this section we focus on the theory. In the next section we analyse the empirical question of the nature of the asymmetric shocks in the Eurozone. We start from a similar trade-off to the one in Figure $7 \cdot 3$, but now we concentrate on the trade-off between flexibility and budgetary union. We define a budgetary union as a (partial) transfer of the national power to tax and to spend to European institutions. A budgetary union has the effect of creating an insurance mechanism that allows countries experiencing bad economic times to be compensated by countries that fare well. The way this trade-off is constructed is as follows (Figure 7.4). On the vertical axis we set out the degree of budgetary union. The higher the degree of budgetary union the more we move upwards along the vertical line. On the horizontal axis we set out the same measure of flexibility as that used in Figure 7.3. The OCAs line now measures the minimum combinations of budgetary union and flexibility needed to make a monetary union economically attractive (higher benefits than costs). It is negatively sloped for the following reason. When budgetary union increases, insurance against asymmetric shocks increases, making monetary union less costly. As a result, there is less need for flexibility. We move upward along the negatively sloped OCAs line.4

4 We call this trade-off the OCAs line because the idea of such a trade-off comes from André Sapir, see A. Sapir, 'Architecture Reform for an Heterogeneous EMU: National vs. European 
This is an important insight. Flexibility may sound great for many economists and central bankers, but it is costly for those people who are forced to be flexible. Flexibility means that these people may have to accept a wage cut or be forced to emigrate. We learn from Figure 7.4 that a movement towards budgetary union alleviates the (painful) need to be flexible. It may also make a monetary union more acceptable to large segments of the population. At the same time, however, it may make those who are asked to transfer revenue unhappy, resisting such a 'Transfer Union'.

We can use the insights of Figure 7.4 to analyse the importance of the nature of the asymmetric shocks. We have made the distinction between asymmetric shocks that are exogenous and permanent, and asymmetric shocks that are temporary and endogenous. We have argued that when a permanent (exogenous) shock occurs, flexibility is the only option to adjust to this shock. By contrast, when business-cycle movements are synchronised it is not optimal to use flexibility. In that case an insurance mechanism is the appropriate way to govern the monetary union. A budgetary union provides this.

It can now be shown that the nature of the shocks influences the slope of the trade-off. 5 When the shocks are mainly of the permanent type, we obtain a steep trade-off. We show this in Figure 7.5. We have also put the Eurozone of 19 members below the $\mathrm{OCA}_{\mathrm{S}}$-line, suggesting that the present Eurozone is not an OCA. The steep trade-off implies that a small increase in flexibility leads us more quickly into the OCA zone than a budgetary union. In the most extreme case - when all shocks are of a permanent nature - the trade-off becomes vertical. In that case no amount of budgetary union will bring us into the OCA-zone. There is then no other way but to increase flexibility.

Things are very different when the shocks are temporary, driven by businesscycle movements. In that case the trade-off is flat (Figure 7.6). As a result, much flexibility is needed to move the Eurozone into the OCA area compared to budgetary union. A relatively small increase in budgetary union will bring us into the OCA-zone. In the most extreme case - when all shocks are of a temporary nature - the trade-off is horizontal. In that case no amount of flexibility will succeed in bringing the Eurozone into the OCA-zone. The only way to achieve optimality will be through a budgetary union.

One complication that arises here has to do with hysteresis. Sometimes temporary shocks can lead to hysteresis effects. For example, a recession typically leads to plant closures and dismissal of workers. To the extent that these

Institutions', contribution to the conference 'Adjustment in European Economies in the Wake of the Economic Crisis', Bank of Portugal, 9 May 2015.

5 We are grateful to Frank Vandenbroucke for suggesting that the nature of the shocks affects the slope of the trade-off. 


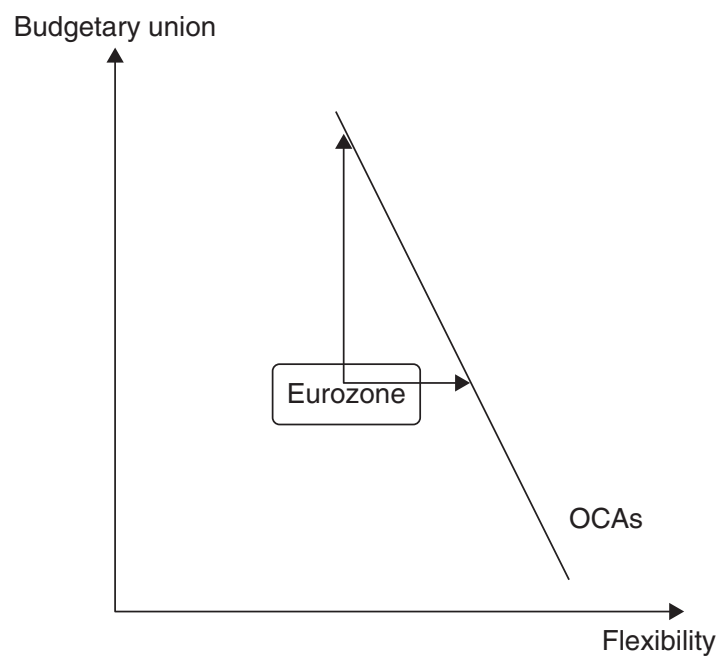

FIGURE 7.5: How to move the Eurozone towards the $\mathrm{OCA}_{\mathrm{S}}$-area when permanent shocks dominate?

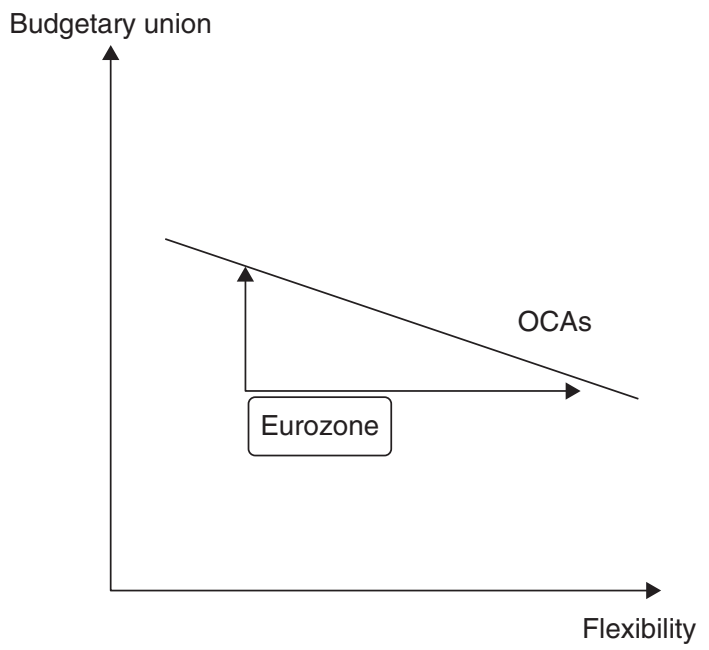

FIGURE 7.6: How to move the Eurozone towards the OCA $\mathrm{S}_{\mathrm{S}}$-area when businesscycle movements dominate?

workers have developed firm specific skills that are lost when the firm disappears, the workers lose part of their human capital making it difficult to find another (comparable) job. Unemployment can then become protracted. Another example relates to the nature of the boom. If, as was the case in 
Ireland and Spain, the boom is concentrated in the housing market, many workers are attracted to this sector during the boom. After the crash they are dismissed. They may find it difficult to use their skills acquired in the housing market in other sectors of the economy. There is a large literature on sources of hysteresis. ${ }^{6}$

The existence of hysteresis has implications for our discussion. It implies that if a business-cycle shock occurs it matters a great deal to try to use stabilisation so as to avoid hysteresis effects. If temporary business-cycle shocks have permanent effects the need to set up schemes that will mitigate the impact of these shocks becomes even more important. Figures 7.5 and 7.6 lead to another interesting insight. Flexibility in labour markets is something national governments can do. There is no need for further integration to increase flexibility. Budgetary union, however, is of a different nature. It requires political integration. In other words, while flexibility is in the realm of national governments, budgetary union is a European affair.7 When shocks are permanent they have to be dealt with at the national level while when shocks are temporary the response should be at the level of the Eurozone.

\subsection{THE NATURE OF SHOCKS IN THE EUROZONE: EMPIRICAL EVIDENCE}

It is not always easy to separate permanent from temporary shocks in economic time series. Here we use a Hodrick-Prescott filter (HP) that allows us to estimate the long-term trend component in GDP. The cyclical component is obtained by subtracting the trend component from the observed GDP (for more detail, see the appendix to this chapter (Section 7.9), where we also analyse the robustness of the results for changes in the smoothness parameter lambda in the HP filter). ${ }^{8}$ The results of this exercise are shown in Figure 7.7. We present, for each Eurozone country, trend growth and the

6 See O.J. Blanchard and H.L. Summers, 'Hysteresis and the European Unemployment Problem' (1986) 1 NBER Macroeconomics Annual 15; L.M. Ball, 'Hysteresis in Unemployment: Old and New Evidence' (2009), US National Bureau of Economic Research (NBER) Working Paper, 14818; A. Fatas and L. Summers, 'The Permanent Effects of Fiscal Consolidations' (2015) available at: voxeu.org/sites/default/files/file/DP10902.pdf (accessed 19 October 2016). Sapir, n. 4 in this chapter.

8 There is a literature based on Blanchard and Quah (O. Blanchard and D. Quah, "The Dynamic Effect of Demand and Supply Disturbances' (1989) 79 American Economic Review 655), which is based on estimating a VAR and, after imposing identifying restrictions, is able to estimate the temporary and the permanent component in output shocks. We discuss this literature in P. De Grauwe and Y. Ji, 'Crisis Management and Economic Growth in the Eurozone', in F. Caselli, M. Centeno, and J. Tavares (eds), After the Crisis: Reform, Recovery and Growth in Europe (Oxford University Press, 2016). 
Growth GDP and Trend GDP, Austria

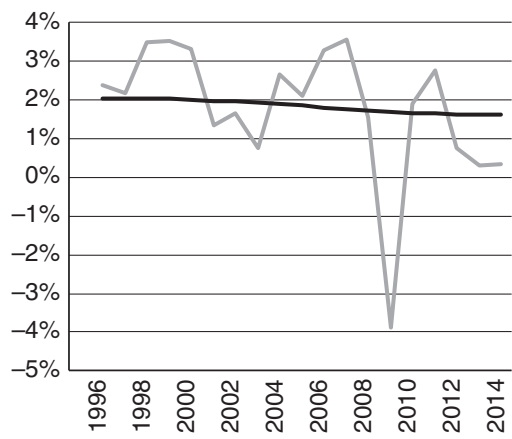

(a)

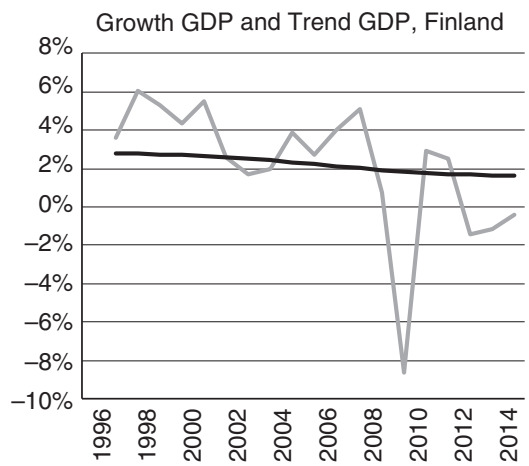

(c)

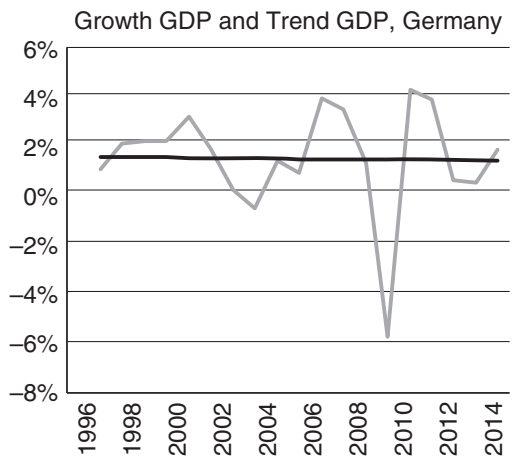

(e)
Growth GDP and Trend GDP, Belgium

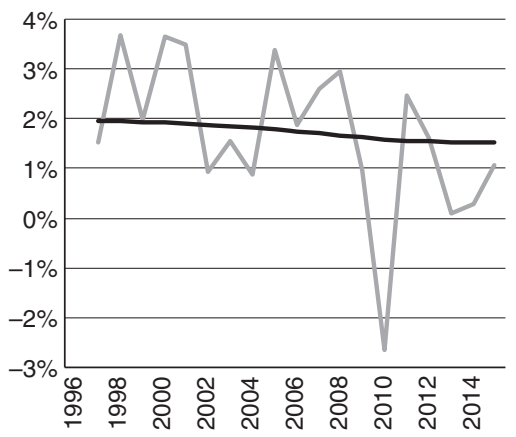

(b)

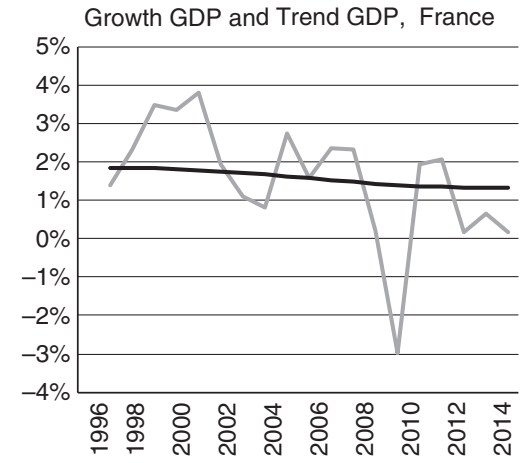

(d)

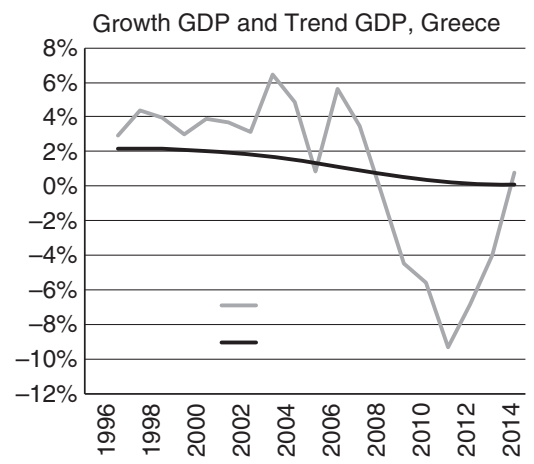

(f)

\section{- Growth GDP $\quad$ Growth Trend GDP}

FIGURE 7.7: Cyclical and trend components in GDP growth (19992014): (a) Austria; (b) Belgium; (c) Finland; (d) France; (e) Germany; (f) Greece; (g) Ireland; (h) Italy; (i) Netherlands; (j) Portugal; (k) Spain.

Sources: Eurostat and own calculations. 


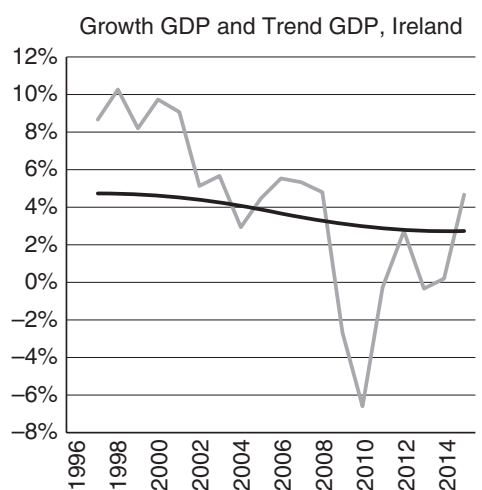

(g)

Growth GDP and Trend GDP, Netherlands

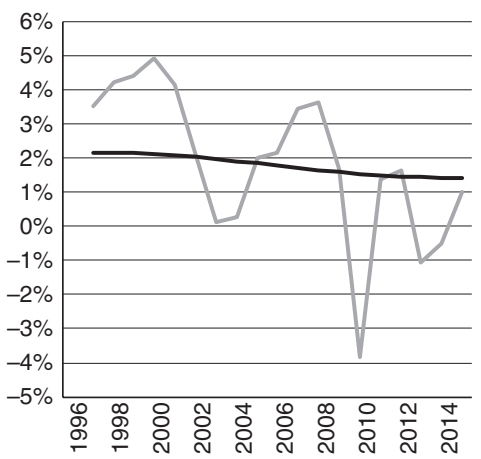

(i)

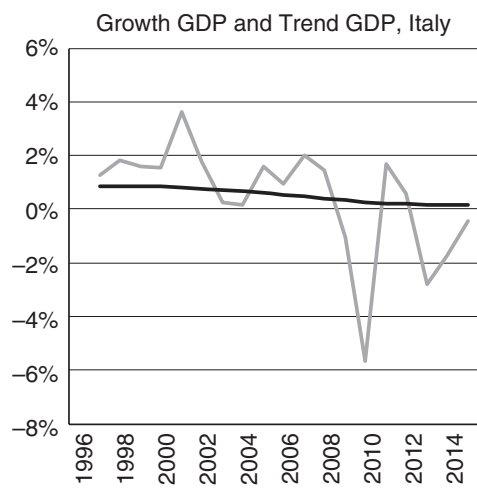

(h)

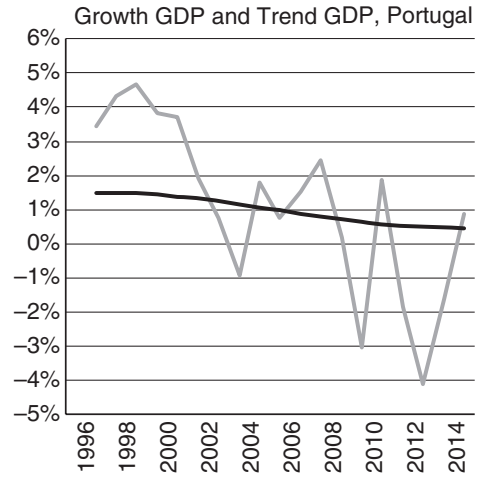

(j)

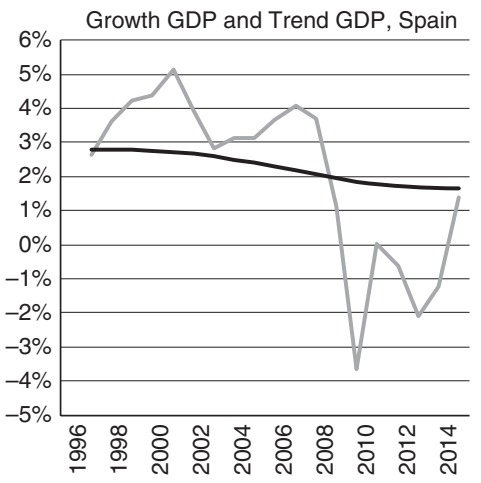

(k)

- Growth GDP - Growth Trend GDP

FIGURE 7.7: (cont.) 
TABLE 7.1: Mean (absolute) trend growth and mean (absolute) business-cycle change in GDP (as a percentage) during 1999-2014

\begin{tabular}{lccc}
\hline \hline & Mean cycle & Mean trend & Ratio \\
\hline Austria & $1.79 \%$ & $1.77 \%$ & 1.01 \\
Belgium & $1.72 \%$ & $1.67 \%$ & 1.03 \\
Germany & $1.55 \%$ & $1.23 \%$ & 1.26 \\
France & $2.15 \%$ & $1.49 \%$ & 1.44 \\
Netherlands & $2.66 \%$ & $1.66 \%$ & 1.60 \\
Finland & $4.35 \%$ & $2.02 \%$ & 2.15 \\
Spain & $4.58 \%$ & $2.07 \%$ & 2.21 \\
Ireland & $8.01 \%$ & $3.35 \%$ & 2.39 \\
Portugal & $3.67 \%$ & $0.81 \%$ & 4.53 \\
Italy & $2.86 \%$ & $0.41 \%$ & 7.05 \\
Greece & $9.09 \%$ & $0.90 \%$ & 10.11 \\
\hline
\end{tabular}

Notes: (as a percentage) during 1999-2014.

Source: Computations based on data from Eurostat.

observed growth rates (the cyclical component is obtained by subtracting the observed from the trend growth).9 Two results stand out. First, we observe for all Eurozone countries (except for Germany) a decline in the long-term growth rate of GDP. This decline is particularly significant in Greece, Ireland, Finland, Spain, Portugal, and Italy. Second, there is great variability in the business-cycle (temporary) component of GDP growth. In order to gauge the relative importance of cyclical and trend components in GDP growth we compare the mean (absolute) cyclical growth of GDP with the (absolute) mean trend growth of GDP for each country. ${ }^{10}$ We show the results in Table 7.1. We observe that for the core countries (Austria, Belgium, Germany, and the Netherlands) the cyclical growth and trend growth components are of similar magnitudes, although the cyclical component is systematically larger than the trend component. In the countries of the periphery (Spain, Portugal, Ireland, Italy, and Greece) this is very different. We observe that for these countries the cyclical growth component is much larger than the trend growth component (the most extreme case being observed for Greece). Thus, in the peripheral

9 We only include the original Eurozone countries. The new Eurozone countries entered too late to provide a sufficiently long time series.

10 As the cyclical component alternates between positive and negative numbers we have to take the absolute values. 
TABLE 7.2: Correlation coefficients of cyclical components of GDP growth

Aus. Bel. Fin. Fra. Ger. Gre. Ire. Ita. Net. Por.

\begin{tabular}{llllllllllll}
\hline Austria & & & & & & & & & & \\
Belgium & 0.9 & & & & & & & & & \\
Finland & 0.9 & 0.9 & & & & & & & & \\
France & 0.9 & 0.9 & 0.9 & & & & & & & \\
Germany & 0.6 & 0.5 & 0.5 & 0.5 & & & & & & \\
Greece & 0.7 & 0.8 & 0.8 & 0.7 & 0.0 & & & & & \\
Ireland & 0.8 & 0.8 & 0.9 & 0.9 & 0.4 & 0.8 & & & & \\
Italy & 0.9 & 0.9 & 0.9 & 0.9 & 0.5 & 0.8 & 0.9 & & & \\
Netherlands & 0.9 & 0.9 & 0.9 & 0.9 & 0.6 & 0.7 & 0.8 & 0.9 & & \\
Portugal & 0.9 & 0.8 & 0.8 & 0.8 & 0.3 & 0.8 & 0.8 & 0.9 & 0.9 & \\
Spain & 0.8 & 0.9 & 0.94 & 0.8 & 0.2 & 0.9 & 0.9 & 0.9 & 0.8 & 0.9 \\
\hline
\end{tabular}

Source: Own calculations based on Eurostat.

countries the GDP growth rates have been dominated by cyclical movements in economic activity of the boom-bust type.

What are the implications of these results? First, since the start of the Eurozone, cyclical (temporary) movements have been the dominant factor behind growth variations in GDP. This is especially the case in those peripheral countries where cyclical movements in economic growth are many times higher than the long-term growth rates. Thus, as mentioned earlier, booms and bust in economic activity seem to be the overwhelming characteristic of movements in GDP in the countries of the periphery.

Second, it appears that the cyclical movements of GDP are highly correlated in the Eurozone. This is made clear by Table 7.2, which shows the correlations in the cyclical components of GDP growth across the Eurozone. We observe high correlation coefficients of bilateral cyclical components of GDP growth, typically 0.8 or more. ${ }^{11}$ It is interesting to note that the country with the lowest correlation coefficients is Germany (although the German correlation coefficients are all positive). Thus, one can conclude that the business cycles of the Eurozone countries were highly correlated. Germany stands out as the country with the lowest (positive) correlations of its business cycle with the rest of the Eurozone.

"We study a behavioural macroeconomic model and show that in such a model 'animal spirits' can easily get correlated internationally, producing high correlations of business cycles. This study can be found in P. De Grauwe and Y. Ji, "The International Synchronisation of Business Cycles: The Role of Animal Spirits' (2017) 28 Open Economies Review 1. 
Thus, the asymmetry between the Eurozone countries is to be found not so much in a lack of correlation in business-cycle movements but in the intensity of the boom-bust dynamics of growth rates. Put differently, Eurozone countries' business cycles seem to have been relatively well correlated. The difference between these countries was that some (mainly in the periphery) experienced much higher variance in business-cycle fluctuations than others (in the core). As a result, the asymmetry between member countries is to be found in the variance of the business cycles. This feature is striking in Figure 7.8, which shows the movements of the business-cycle components in the different Eurozone countries. These appear to move together but are of

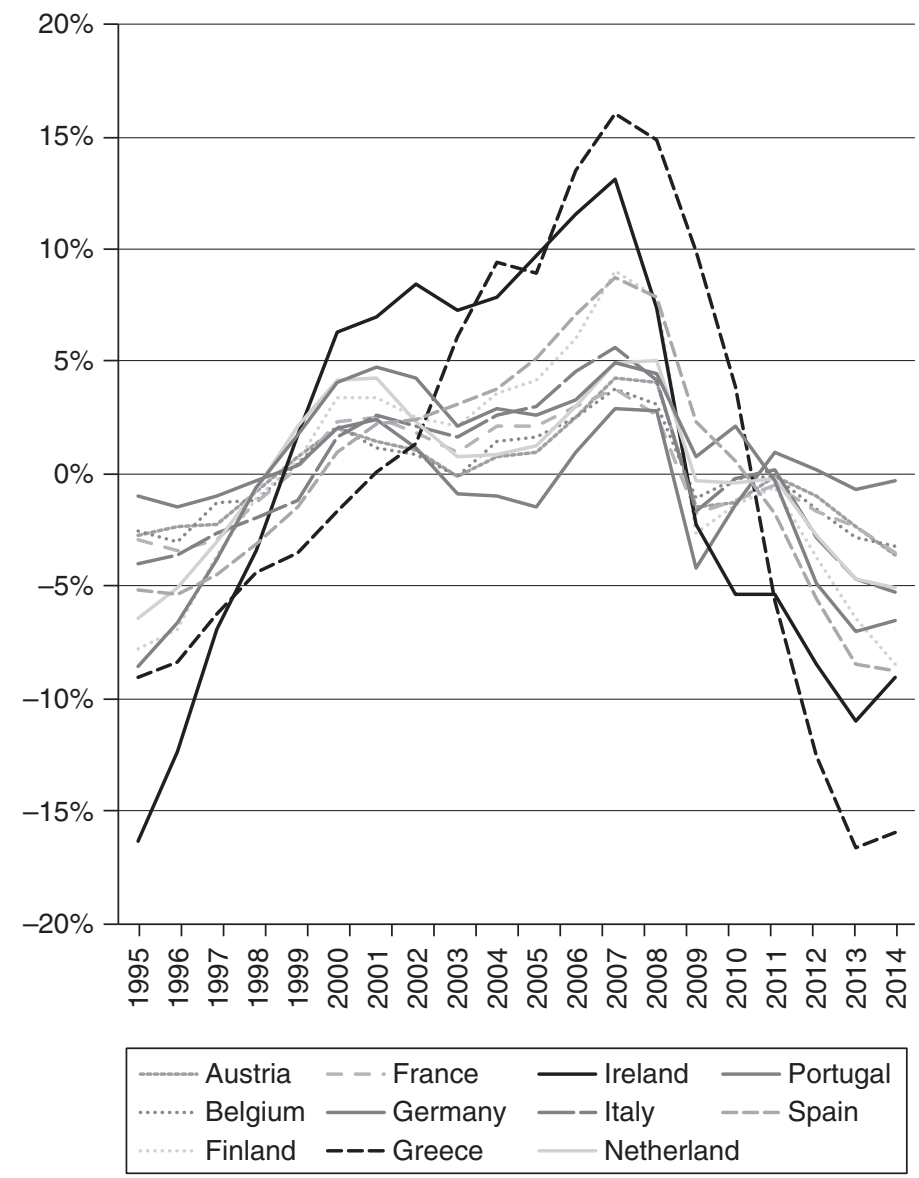

FIGURE 7.8: Business-cycle component of GDP growth.

Source: Own calculation based on Eurostat. 
TABLE 7.3: Slope of regression domestic cycle on euro-cycle

\begin{tabular}{ll}
\hline \hline & Slop \\
\hline Germany & 0.21 \\
Belgium & 0.48 \\
Austria & 0.49 \\
France & 0.55 \\
Italy & 0.77 \\
Netherlands & 0.80 \\
Portugal & 1.02 \\
Finland & 1.21 \\
Spain & 1.22 \\
Ireland & 2.07 \\
Greece & 2.18 \\
\hline
\end{tabular}

Source: Own calculations.

very different amplitude. Some countries like Ireland and Spain experience a very strong boom and later bust, while countries like Belgium, Austria, and Germany experience similar cycles but of much less amplitude.

In order to obtain a more precise estimate of the asymmetry in the amplitudes of the business cycles, we regressed each country's domestic cyclical component on the Eurozone common cyclical component. The estimated slope coefficients reveal the extent to which the domestic cycles are smaller or lower in amplitude than the common cycle. The estimated slope coefficients are presented in Table 7.3. It is striking to find how different these slope coefficients are. Germany, Belgium, Austria, and France have slope coefficients that are significantly lower than 1 , suggesting cycles of significantly lower amplitude than the euro-cycle. Conversely, Finland, Spain, and especially Ireland and Greece, have slope coefficients significantly higher than 1 . This suggests that these countries experienced much higher amplitudes in their business cycles than the common euro-cycle.

\section{$7 \cdot 5$ WHAT KIND OF FLEXIBILITY}

In the previous sections we lumped together labour-market and product market flexibility. This may make sense when discussing the trade-off between stabilisation and flexibility but not when analysing the long-term growth potential of countries. Labour-market and product market flexibility 
may have different implications for long-term growth. In order to analyse this issue, in a previous study we performed an econometric analysis of the separate effects of labour-market and product market rigidities in the OECD countries during the period $1980-2014 .{ }^{12}$ We used standard econometric growth analysis of panel data. The measures of labour-market rigidity were the OECD employment protection index and for product market rigidity the OECD product market legislation index. The most striking aspect of the results is the finding that these measures of the labour and product market rigidities do not seem to have any influence on the growth rate of GDP per capita in OECD countries. Similar results were obtained by IMF.13

The conclusion is that employment protection is of no visible importance for economic growth may seem surprising. The 'Brussels-Frankfurt consensus' has stressed that employment protection has a negative effect on hiring and in so doing reduces prospects for growth. This may be true but there is another phenomenon that may more than compensate the positive effect of flexibility. In economies where employment protection is weak the incentives for firms to invest in its labour force is weak. When turnover is high firms are unlikely to invest in personnel that are likely to quit early. In addition, employees that can be fired quickly have equally weak incentives to invest in firm-specific skills. As a result, labour productivity is negatively affected. More generally, the quality of human capital will be low.

The same conclusion holds for product market regulations. Product market regulations do not seem to matter in the process of economic growth. Again this goes against current mainstream thinking, which has been much influenced by, among others, Aghion et al., which stresses that the model of perfect competition with free entry and price flexibility boosts innovation among firms that are close to the technological frontier. ${ }^{14}$ There is an older literature, however, going back to Joseph Schumpeter stressing that innovation, investment and growth are better promoted in an environment of market imperfections and market power. The empirical evidence suggests that both opposing views may be at work, thereby offsetting each other.

${ }_{12}$ De Grauwe and Ji, n. 8 in this chapter.

13 International Monetary Fund, World Economic Outlook: Uneven Growth - Short- and Longterm Factors (International Monetary Fund, 2015), pp. 104-7 (chapter 3, Box 3.5 on "The Effects of Structural Reforms on Total Factor Productivity').

${ }^{14}$ P. Aghion, C. Harris, P. Howitt, and J. Vickers, 'Competition, Imitation and Growth with Stepby-Step Innovation' (2001) 68 Review of Economic Studies 467. 


\subsection{IMPLICATIONS FOR THE GOVERNANCE OF THE EUROZONE}

The findings reported in the previous sections put the need for stabilisation in the Eurozone in a new light. We analyse two implications that involve steps towards budgetary integration. First, the finding of the overwhelming importance of the cyclical and temporary component of output growth should lead to the conclusion that efforts to stabilise the business cycle should be strengthened relative to the efforts that have been made to impose structural reforms. In terms of our theoretical analysis this means that Figure 7.6 is probably the relevant one. Again, this does not mean that flexibility can be disposed of.

\subsubsection{Common Unemployment Insurance}

A second implication of our empirical results relates to the many proposals made to create a fiscal space at the Eurozone level in the form of a common unemployment insurance system. ${ }^{15}$ The proposals for such an insurance system have very much been influenced by the standard assumption made in the OCA-theory that shocks are asymmetric, in other words, that when one country experiences a recession, and thus increasing unemployment, the other country experiences a boom, and declining unemployment. This facilitates the workings of the common unemployment insurance system. The booming country transfers resources to the country in a recession and thereby smooths the business cycles in the two countries. Technically and politically such a system encounters relatively few problems.

Problems may arise when, as we have found, business cycles are relatively well synchronised but of very different amplitudes in the different member countries. In that case most countries will tend to experience a recession at about the same time; in some countries the recession will be mild but in others very intense. This creates both an economic and a political problem. First, countries with a mild recession are asked to transfer resources to countries experiencing a stronger recession. This tends to reduce the intensity of the

15 See, for example, H. Van Rompuy, "Towards a Genuine Economic and Monetary Union, Report in Close Collaboration with J.M. Barroso, J.C. Juncker, and M. Draghi ("The Four Presidents Report")' (2012), available at: ec.europa.eu/priorities/sites/beta-political/files/ 5-presidents-report_en.pdf (accessed 20 October 2016); Tommaso Padoa-Schioppa Group, 'Completing the Euro: A Road Map towards Fiscal Union in Europe' (2012), available at: www.notre-europe.eu/media/completingtheeuroreportpadoa-schioppagroupnejunezo12. pdf?pdf=ok (accessed 20 October 2016); M. Beblavy, G. Marconi, and I. Maselli, 'European Unemployment Benefits Scheme: The Rationale and the Challenges Ahead' (2015), available at: www.ceps.eu/system/files/CEPS\% 20 SR\% 20No\% $20119 \%$ 20EUBS_o.pdf (accessed 20 October 2016). 
recession in the latter country at the expense of making it more intense in the former country. It is not clear that this improves welfare. Second, it is likely to create important political problems in the former country that is asked to transfer resources when the economy is not doing well. Another way to formulate the previous insights is the following. The traditional proposals for a Eurozone unemployment insurance mechanism are predicated on the view that there is a need to smooth differences in unemployment changes across countries. That is, it is assumed that some countries experience increases, others declines in unemployment. The insurance mechanism then smooths these intercountry differences. We have noted, however, that this is not a typical Eurozone asymmetry. What we found is that most countries are likely to experience a boom and a recession at about the same time, with different intensities and amplitudes. There is therefore relatively little need for intercountry smoothing of business-cycle movements. The more pressing need is to smooth volatilities over time.

The previous analysis suggests that common unemployment insurance schemes should put emphasis on smoothing over time and not so much on intercountry smoothing. This can be achieved by allowing the common unemployment insurance scheme to accumulate deficits and surpluses over time. The fiscal rule that could be imposed is that the insurance scheme balances over the business cycle. Beblavy and Maselli have performed interesting simulations of several schemes that impose such a fiscal rule. ${ }^{16}$ In general it appears from these simulations that such an insurance mechanism can be implemented. Such a rule would make it possible to automatically balance the need for intercountry and intertemporal smoothing.

The previous analysis makes clear, however, that given the importance of common business-cycle movements, a common unemployment insurance mechanism will need a capacity to issue bonds during recessions when the payments made by the insurance scheme will exceed the contributions by the Member States. During these periods the deficits of the scheme will have to be financed by the issue of common bonds, which one may want to call Eurobonds. Put differently, the common unemployment insurance mechanism will have to work like a common fund that is capable of issuing debt during recessions. If this is not allowed, a common unemployment insurance system cannot contribute much to common stabilisation efforts. Thus,

${ }_{16}$ M. Beblavy and I. Maselli, 'An Unemployment Insurance Scheme for the Euro Area: A Simulation Exercise of Two Options' (2014), available at: www.ceps.eu/system/ files/CEPS\%zoSpecial\%zoReport\%zoAn\%zoEU\%zoUnemployment\%zoInsurance\%zo Scheme\% zoBeblavy\% zoand\% zoMasselli.pdf (accessed zo October 2016). 
a workable common unemployment benefit scheme will necessarily imply some form of budgetary union.

Such a budgetary union can be kept relatively mild by imposing the fiscal rule mentioned earlier: that during common booms, the bonds issues during the recession are retired, thereby insuring that there is no long-term accumulation of common bonds. Today, this is probably as far as one can go in the direction of a budgetary union.

\subsubsection{National Stabilisation?}

In principle, intertemporal smoothing could be done at the national level, by allowing the national budgets to do the job. However, the large differences in the amplitude of business-cycle movements make such a purely national approach problematic, as it leads to large differences in the budget deficits and debt accumulation between countries. These differences quickly spill over into financial markets when countries that are hit very hard by a downward movement in output are subjected to sudden stops and liquidity crises. ${ }^{17}$ This is likely to force them to switch off the automatic stabilisers in their national budgets. ${ }^{18}$ As we argued, this can push countries into a bad equilibrium. Put differently, in the absence of a budgetary union, large differences in the amplitude of the business cycles are likely to hit the countries experiencing the more severe recession by 'sudden stops', that is to say, by large liquidity outflows that force them to abandon any ambition to stabilise the business-cycle shocks. In addition, these liquidity outflows are inflows in some other countries in the monetary union, typically those that are least hit by the recession. ${ }^{19}$ Their economic conditions improve at the expense of the others. The stabilisation of common business shocks with different amplitudes at the national level makes the system unstable.

In this respect, the research of Alcidi and Thirion is relevant. ${ }^{20}$ These authors find that while the core Eurozone countries have been able to stabilise part

17 See P. De Grauwe, 'The Governance of a Fragile Eurozone' (2011) CEPS Working Documents, No. 346.

18 P. De Grauwe and Y. Ji, 'Self-fulfilling Crises in the Eurozone: An Empirical Test' (2012) 34 Journal of International Money and Finance 15.

19 This is confirmed by the empirical work of Furceri and Zdzienicka (D. Furceri and M.A. Zdzienicka, 'The Euro Area Crisis: Need for a Supranational Fiscal Risk Sharing Mechanism?' (2013) IMF Staff Discussion Note, No. 13-198) and Hoffmann and Nitschka (M. Hoffmann and T. Nitschka, 'Securitization of Mortgage Debt, Domestic Lending, and International Risk Sharing' (2012) 45 Canadian Journal of Economics 493) who find that during recessions risk sharing through financial markets declines dramatically.

20 C. Alcidi and G. Thirion, Feasibility and Added Value of a European Unemployment Benefit Scheme: Interim report (CEPS, 2015). 
(about 50 per cent) of the business-cycle shocks at the national level since the eruption of the debt crisis in 2010, the peripheral countries have been unable to do so, and also unable to profit from insurance mechanisms at the level of the Eurozone. As a result, most (9o per cent) of the business-cycle shocks had to be absorbed by drops in consumption (and therefore in employment). National stabilisation efforts do not work but introduce an element of instability into a monetary union, mainly because they leave the countries most hit by the business-cycle shocks unable to stabilise. Thus, when business-cycle shocks dominate (as we have shown in the previous section) it will be necessary to follow a common approach to the stabilisation of the business cycles. The common unemployment insurance mechanisms discussed in the previous section move us in this direction. Whether these schemes are important enough to perform a significant stabilising role remains to be seen. The common insurance mechanisms now being proposed have a relatively small intertemporal smoothing component, amounting to no more than 0.1 to 0.2 per cent of GDP over the business cycle, certainly insufficient to produce a significant intertemporal smoothing at the EU-level. ${ }^{21}$

Thus, in the long run further steps towards a budgetary union will be necessary. By centralising part of the national budgets into a common budget managed by a common political authority, the different increases in budget deficits following from a (common) recession translate into a budget deficit at the union level. As a result, the destabilising flows of liquidity between countries disappear, and the common budgetary authority can allow the automatic stabilisers in the budget to do their role in smoothing the business cycle. In fact, because a common budget also generates implicit intercountry transfers the countries with the deepest recession will profit from the automatic stabilising features of the common budget most. As a result, a common budget provided the most effective way to stabilise the business cycle. It is clear, however, that a budgetary union in which a significant part of national taxation and spending is transferred to a European government and parliament is far off. For the time being less ambitious efforts, such as the common unemployment insurance systems, are all that is feasible. They are important though in that they make clear the direction the Eurozone institutions will have to take in the future. ${ }^{22}$

${ }^{21}$ Beblavy and Maselli, n. 16 in this chapter.

22 See also, on this, F. Vandenbroucke, "The Case for a European Social Union. From Muddling Through to a Sense of Common Purpose', in B. Marin (ed.), The Future of Welfare in a Global Europe (Aldershot, 2015). 


\subsection{COMPLETING THE MONETARY UNION WITH POLITICAL UNION}

The present institutional setup of the Eurozone is characterised by the fact that a number of bureaucratic institutions have acquired significant responsibilities without political accountability. Thus, there has been a transfer of sovereignty without a concomitant democratic legitimacy. Here we concentrate on the European Commission. Elsewhere, we discussed the European Central Bank. ${ }^{23}$

\subsubsection{The European Commission and Political Union}

The European Commission has seen its responsibilities increase since the eruption of the sovereign debt crisis in the Eurozone. This has been motivated by the desire of the creditor nations to impose budgetary and macroeconomic discipline on the debtor nations. As a result, the Stability and Growth Pact has been strengthened, and the European Commission has been entrusted with the responsibility of monitoring macroeconomic imbalances and to force debtor nations to change their macroeconomic policies. ${ }^{24}$ The idea that macroeconomic imbalances should be monitored and controlled is a good one. The emergence of such imbalances was at the origin of the euro-crisis. Yet the way this idea has been implemented is unsustainable in the long run. The new responsibilities of the European Commission create a problem of democratic legitimacy. The European Commission can now force countries to raise taxes and reduce spending without, however, having to bear the political cost of these decisions. These costs are borne by national governments. This is a model that cannot work. Governments that face the political costs of spending and taxation will not continue to accept the decisions of unelected officials who do not face the cost of the decisions they try to impose on these governments. Sooner or later governments will go on strike, like the German and French governments did in 2003-04. Only the small countries (Portugal, Belgium, Ireland, etc.) will have to live with this governance. Large countries will not.

\subsubsection{Bureaucratic versus Political Integration}

Increasingly, European integration has taken the form of bureaucratic integration as a substitute for political integration. This process has started as soon as the European political elite became aware that further political integration

23 De Grauwe, n. 2 in this chapter.

24 In principle, the macroeconomic imbalance procedure should work symmetrically. It is, however, very unlikely to work that way. In fact, we see already today that the European Commission exerts more pressure on deficit countries than on surplus countries. 
would be very difficult. This process has become even stronger since the start of the sovereign debt crisis in the Eurozone. The outcome of this crisis has been that the European Commission and the European Central Bank have seen their powers increase significantly, without any increase in their accountability. More and more these two institutions impose decisions that affect millions of people's welfare, but the people who are affected by these decisions do not have the democratic means to express their disagreements. Political scientists make a distinction between output and input legitimacy. Output legitimacy means that a particular decision is seen to be legitimate if it leads to an increase in general welfare. In this view, a government that is technocratic can still be legitimate if it is perceived to improve welfare. This view is very much influenced by the Platonic view of the perfect State. This is a State that is run by benevolent philosophers who know better than the population what is good for them and act to increase the country's welfare. Input legitimacy means that political decisions, whatever their outcome, must be based on a process that involves the population, through elections that allow people to sack those who have made bad decisions.

Much of the integration process in Europe has been based on the idea of output legitimacy. The weak part of that kind of legitimacy becomes visible when the population is not convinced that what the philosophers at the top have decided, has improved welfare. That is the situation today in Europe. In many countries there is a perception that the decisions taken in Brussels and Frankfurt have harmed their welfare.

\subsection{CONCLUSION}

Since the sovereign debt crisis in the Eurozone, member countries have been pushed towards introducing more flexibility into labour and product markets. This drive towards structural reforms was very much influenced by the traditional theory of OCA. This theory stresses that in the face of asymmetric shocks member countries should have a sufficient degree of labour and product market flexibility to adjust to these shocks. Without such flexibility adjustment will be impossible, thereby undermining the sustainability of the monetary union. The underlying assumption of the OCA prescription for structural reform is that asymmetric shocks are permanent (such as permanent changes in preferences or productivity shocks). When the shocks are temporary it does not follow that more flexibility is the answer. More specifically, when the shocks are the result of unsynchronised business-cycle movements, the way to deal with them is by stabilisation efforts. In this chapter we have provided empirical evidence to suggest that the most significant shocks 
in the Eurozone have been the result of boom and bust, driven by waves of optimism and pessimism. These business-cycle movements have been relatively well-synchronised. What was not synchronised was the amplitude of these business-cycle movements, where some countries experienced much greater amplitude in business cycles than others. In principle, these businesscycle movements could be stabilised at the national level without the need for budgetary union. However, as the amplitude of these movements is so different, countries experiencing the deepest recession are likely to be hit by 'sudden stops', meaning liquidity outflows triggered by fear and panic, which forces them to switch off the automatic stabilisers in the budget, preventing them from conducting any stabilisation. We argued that the best possible way to deal with the business-cycle movements whose amplitude is unsynchronised is by introducing a budgetary union. By centralising part of the national budgets into a common budget managed by a common political authority, the various increases in budget deficits following from a (common) recession translate into a budget deficit at the union level. As a result, the destabilising flows of liquidity between countries during the recession disappear, and the common budgetary authority can allow the automatic stabiliser in the common budget to perform its role in smoothing the business cycle. It is highly unlikely that the governance of the Eurozone will move in the direction of creating institutions capable of providing the necessary stabilisation of booms and busts that national governments are no longer able to provide. The willingness to move in this direction is minimal. This has much to do with the absence of a 'deep variable' in the monetary union. This deep variable is the sense of belonging to the same (European) nation and that creates the political basis for organising transfers between countries. The absence of this deep variable makes it inevitable that one looks for schemes that introduce some stabilisation at the Eurozone level without going all the way towards budgetary union.

We discussed common unemployment insurance schemes that are now being proposed and stressed that these have to put more emphasis on intertemporal insurance and less on intercountry insurance. This also implies that they should have the capacity to issue bonds during recessions, and to do the opposite during an economic boom, making sure that over the business cycle there would be no net issue of common bonds.

The unwillingness to create a political union has also led to a continuing temptation to resort to technical solutions to the problem. Thus, there has been a proliferation of technical schemes to introduce Eurobonds. ${ }^{25}$ We have

25 See J. Delpla and J. Von Weizsäcker, 'The Blue Bond Proposal' (2010) 2010 Bruegel Policy Brief 1; P. De Grauwe and W. Moesen, 'Gains for All: A Proposal for a Common Euro 
discussed a common unemployment insurance mechanism in this chapter. They are necessary to indicate the direction in which the Eurozone will have to move. There is a danger, however, that they create a fiction that technical solutions (and therefore also bureaucratic integration) can be a substitute for political unification. As a result, they comfort policy-makers in their decision to set aside all further attempts towards a political union.

\section{$7 \cdot 9$ APPENDIX}

As suggested in the main text, the choice of the smoothing parameter (lamda) in the Hodrick-Prescott (HP) filter has a significant influence on the estimate of the cyclical and permanent components of GDP-growth. In this appendix we illustrate this by comparing estimates, using a high and a low lamda. The high lamda is the same as the one used in the text and was set equal to 1200; the low lamda was set equal to 100. We compare the results in Figure 7.9. It is immediately evident that in the low lamda estimates the long-term growth line follows the observed output growth line more closely. As a result, the cyclical component is on average smaller than in the high lamda case. This is made clear in Table 7.4, which shows the mean absolute changes in the trend and cyclical components. Even in the case of a low lamda we find that the peripheral countries have been subjected to larger cyclical than permanent movements in output.

Table 7.5 presents the correlation coefficients of the cyclical components of GDP growth for low lamda. It should be compared with Table 7.2 in the text. We observe that in the low lamda estimates the correlation coefficients are of a similar order of magnitude as in the high lamda case. Thus, one of our main conclusions, that business cycles have been highly correlated, is maintained. This is also made clear in Figures 7.10 and 7.11 that show the evolution of the business-cycle component in the two estimates. Obviously, in the low lamda estimate the business-cycle components are generally lower than in the high lamda estimate. In both cases, though, we observe similarly correlated booms and busts in the Eurozone. And, as Figure 7.12 indicates, the divergence in the amplitude of the business cycles across countries tends to increase during the boom years prior to the crisis. This

Bond' (2009) 44 Intereconomics 132; J. Von Hagen and G.W. Hammond 'Regional Insurance against Asymmetric Shocks: An Empirical Study for the European Community' (1998) 66 The Manchester School 331; J. Drèze, A. Durré, and J. Carpantier, 'Fiscal Integration and Growth Stimulation in Europe' (2012) 80 Recherches économiques de Louvain 5; H. Enderlein, L. Guttenberg, and J. Spiess, Blueprint for a Cyclical Shock Insurance in the Euro Area, Studies \& Reports No. 100 (Jacques Delors Institute, 2013). 


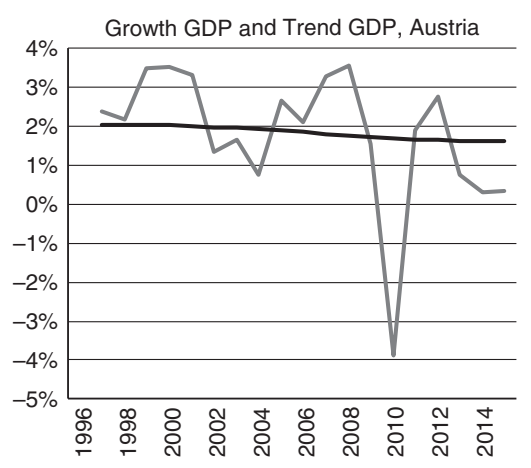

(a)

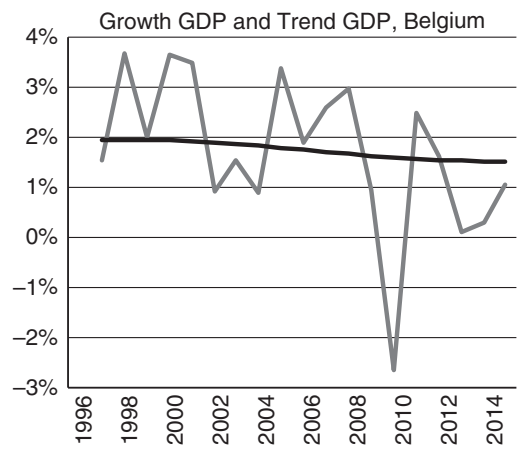

(c)

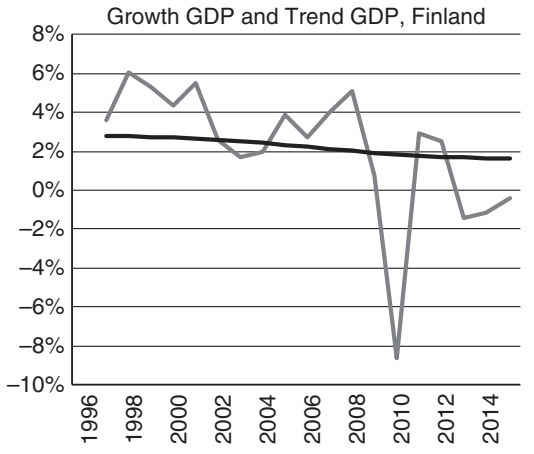

(e)

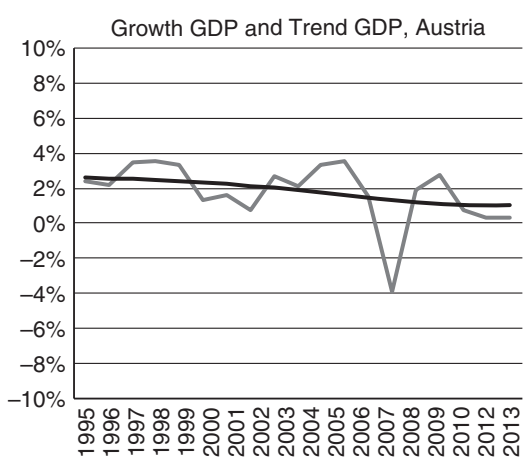

(b)

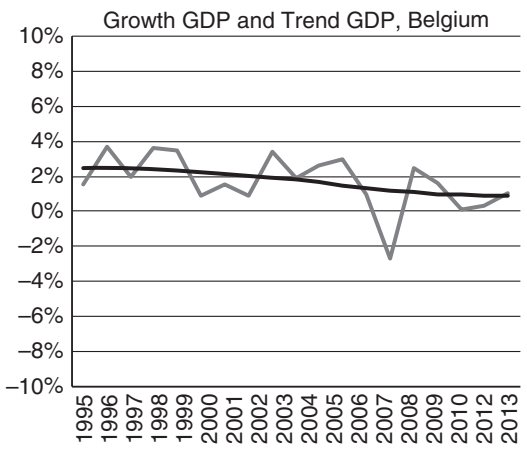

(d)

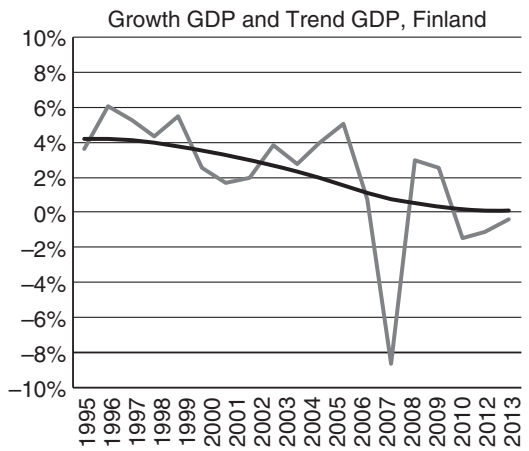

(f)

\section{- Growth GDP $\quad$ Growth Trend GDP}

FIGURE 7.9: Cyclical and trend components in GDP growth (1999-2014), sideby-side comparison high lamda (HL) (Figure 7.7) and low lamda (LL): (a) Austria (HL); (b) Austria (LL); (c) Belgium (HL); (d) Belgium (LL); (e) Finland (HL); (f) Finland (LL); (g) France (HL); (h) France (LL); (i) Germany (HL); (j) Germany (LL); (k) Greece (HL); (l) Greece (LL); (m) Ireland (HL); (n) Ireland (LL); (o) Italy (HL); (p) Italy (LL); (q) Netherlands (HL); (r) Netherlands (LL); (s) Portugal (HL); (t) Portugal (LL); (u) Spain (HL); (v) Spain (LL).

Sources: Eurostat and own calculations. 


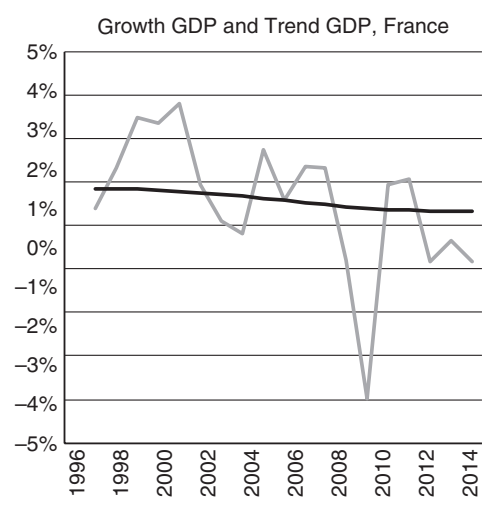

(g)

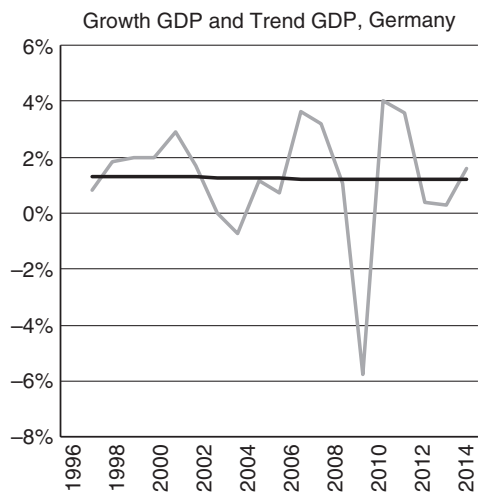

(i)

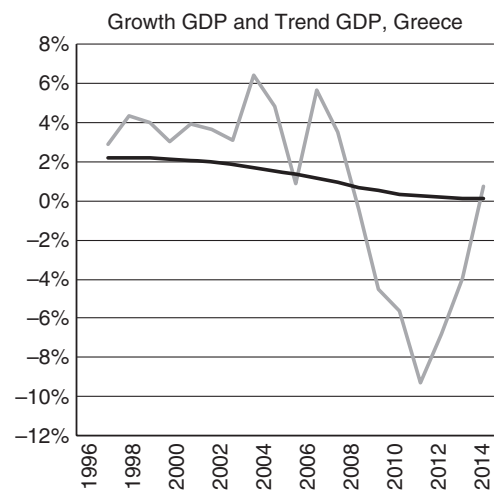

(k)

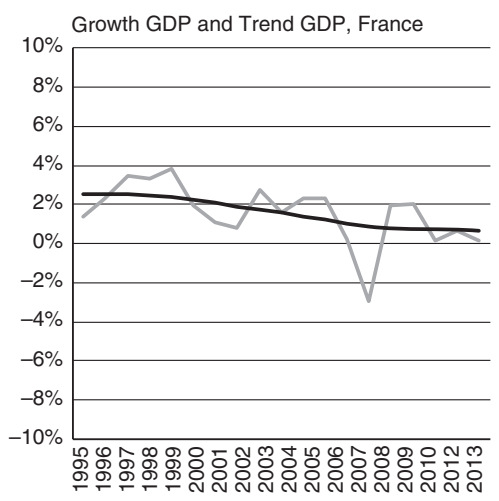

(h)

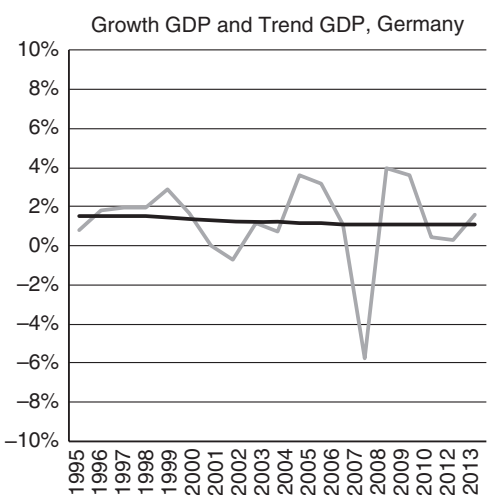

(j)

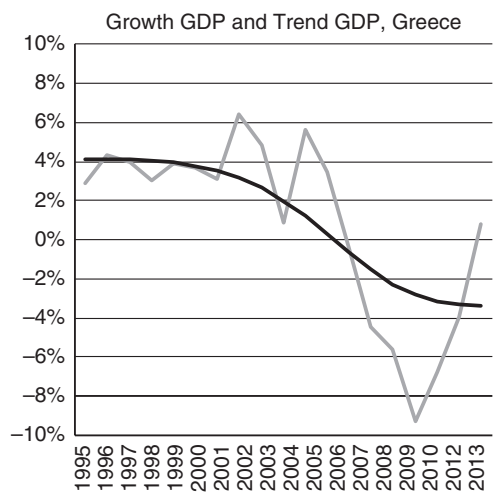

(l)

\section{- Growth GDP — Growth Trend GDP}

FIGURE 7.9: (cont.) 


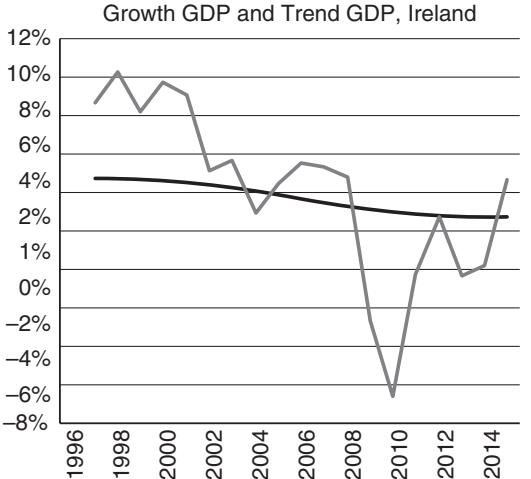

(m)

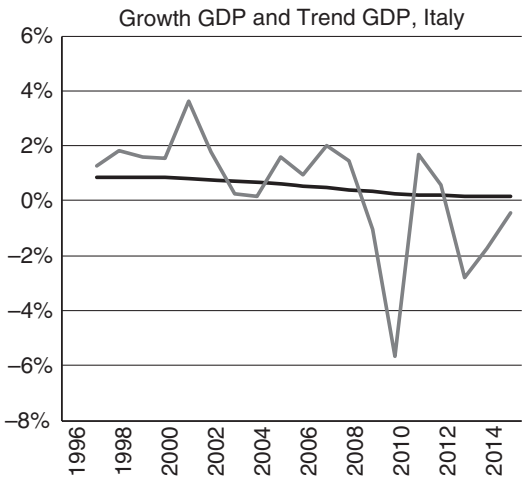

(o)

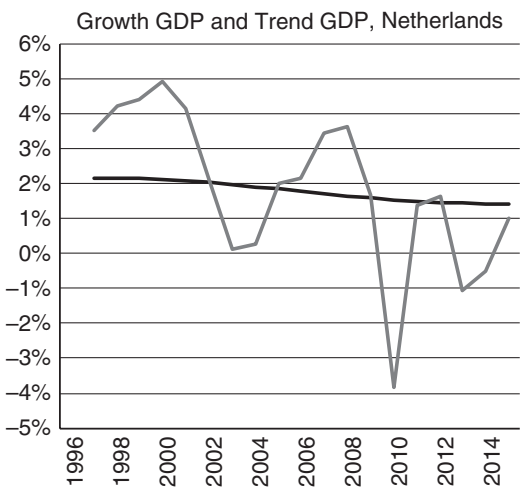

(r)

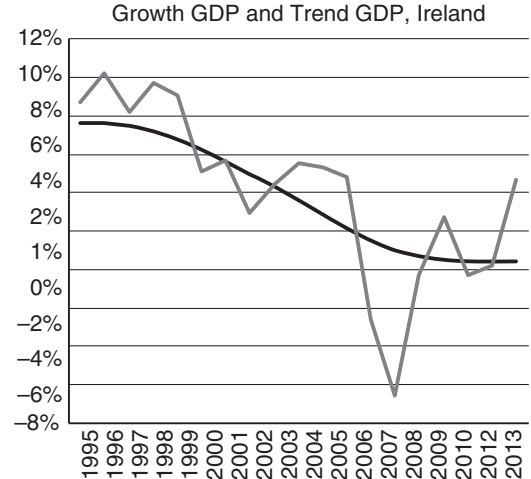

(n)

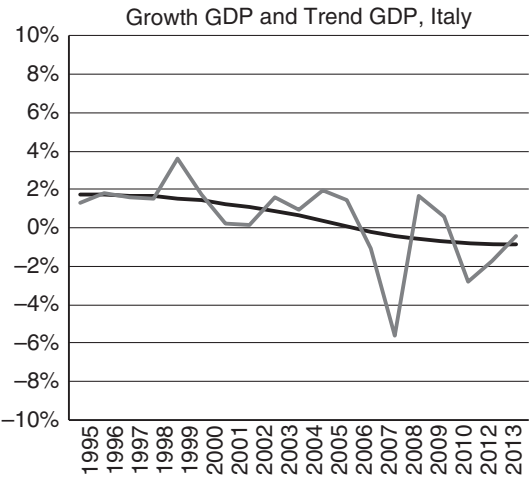

(p)

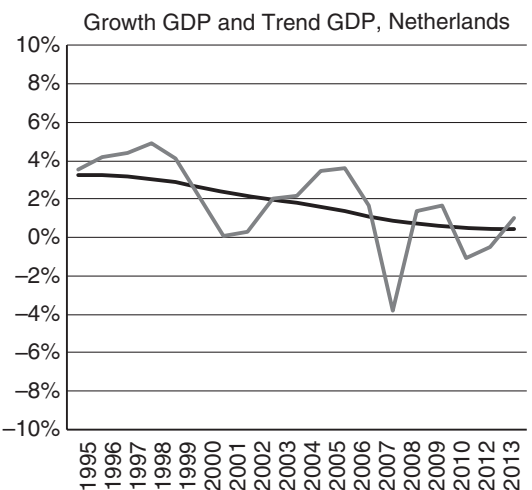

(s)

— Growth GDP — Growth Trend GDP

FIGURE 7.9: (cont.) 


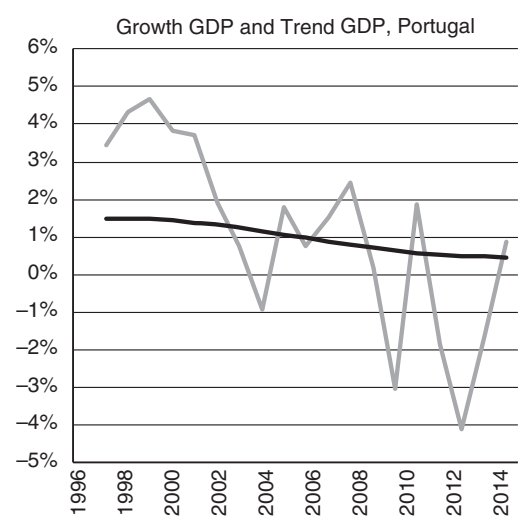

(s)

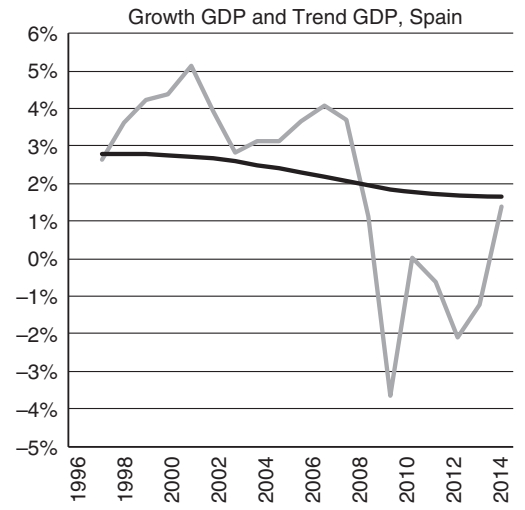

(u)

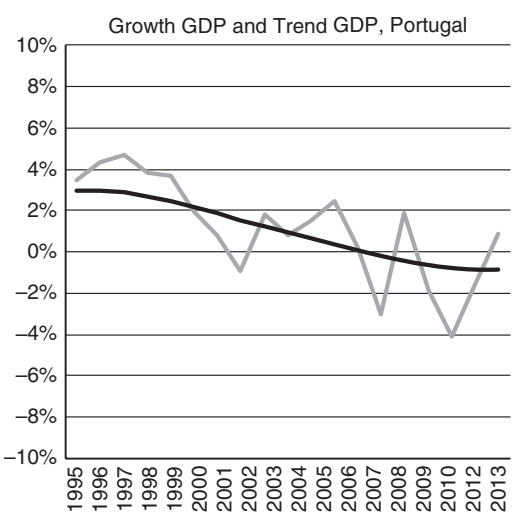

(t)

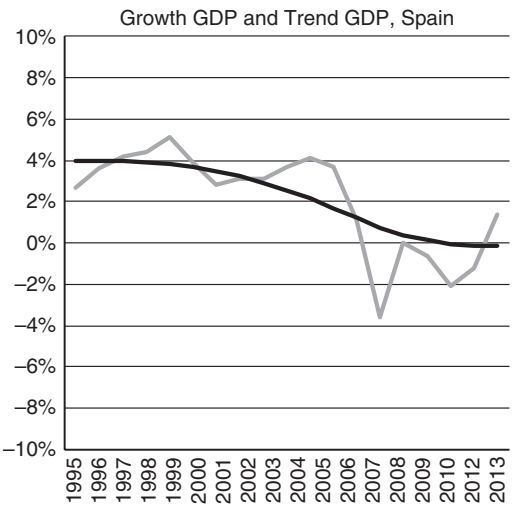

(v)

Growth GDP — Growth Trend GDP

FIGURE 7.9: (cont.) 
TABLE 7.4: Mean (absolute) trend growth and mean (absolute) business-cycle change in GDP (as a percentage) during 1999-2014, side-by-side comparison low lamda and high lamda (Table 7.1)

\begin{tabular}{|c|c|c|c|c|c|c|c|}
\hline \multicolumn{4}{|c|}{ Low lamda } & \multicolumn{4}{|c|}{ High lamda } \\
\hline & $\begin{array}{l}\text { Mean } \\
\text { cycle }\end{array}$ & $\begin{array}{l}\text { Mean } \\
\text { trend }\end{array}$ & Ratio & & $\begin{array}{l}\text { Mean } \\
\text { cycle }\end{array}$ & $\begin{array}{l}\text { Mean } \\
\text { trend }\end{array}$ & Ratio \\
\hline Belgium & 0.97 & 1.47 & 0.66 & Austria & $1.79 \%$ & $1.77 \%$ & 1.01 \\
\hline Austria & $1.18 \%$ & $1.5^{8}$ & 0.75 & Belgium & $1.72 \%$ & $1.67 \%$ & 1.03 \\
\hline Spain & 1.69 & 2.22 & 0.76 & Germany & $1.55 \%$ & $1.23 \%$ & 1.26 \\
\hline France & 1.04 & 1.27 & 0.82 & France & $2.15 \%$ & $1.49 \%$ & 1.44 \\
\hline Portugal & 1.63 & 1.40 & 1.16 & Netherlands & $2.66 \%$ & $1.66 \%$ & 1.60 \\
\hline Netherlands & 1.61 & 1.33 & 1.21 & Finland & $4.35 \%$ & $2.02 \%$ & 2.15 \\
\hline Germany & 1.49 & 1.18 & 1.27 & Spain & $4.58 \%$ & $2.07 \%$ & 2.21 \\
\hline Ireland & 3.26 & $2.4^{8}$ & 1.31 & Ireland & $8.01 \%$ & $3.35 \%$ & 2.39 \\
\hline Finland & 2.08 & 1.53 & 1.36 & Portugal & $3.67 \%$ & $0.81 \%$ & 4.53 \\
\hline Italy & 1.37 & 0.96 & 1.42 & Italy & $2.86 \%$ & $0.41 \%$ & 7.05 \\
\hline Greece & 4.50 & 2.85 & $1.5^{8}$ & Greece & $9.09 \%$ & $0.90 \%$ & 10.11 \\
\hline
\end{tabular}

Notes: see Table 7.1.

Source: Computations based on data from Eurostat.

is also what we found using estimates with a high lamda. Thus, one of our major empirical conclusions still stands, even when one uses a low lamda. This is that the asymmetry in the business cycles of the Eurozone countries is to be found in the divergence in the amplitude of the business cycle. The business cycles themselves tended to be highly correlated. There is reason to believe that the low lamda estimates bias the business-cycle components downwards and thus the long-term growth component upwards (in absolute value). This is made clear from Tables 7.6, which compares the estimates of long-term growth in 1995 and 2014 in the two lamda scenarios. We find that in the low lamda estimates the decline in long-term growth in a number of periphery countries is implausibly high. In the cases of Ireland and Greece long-term growth declines by more than 7 percentage points. (The corresponding declines in the high lamda case is 2 per cent.) 


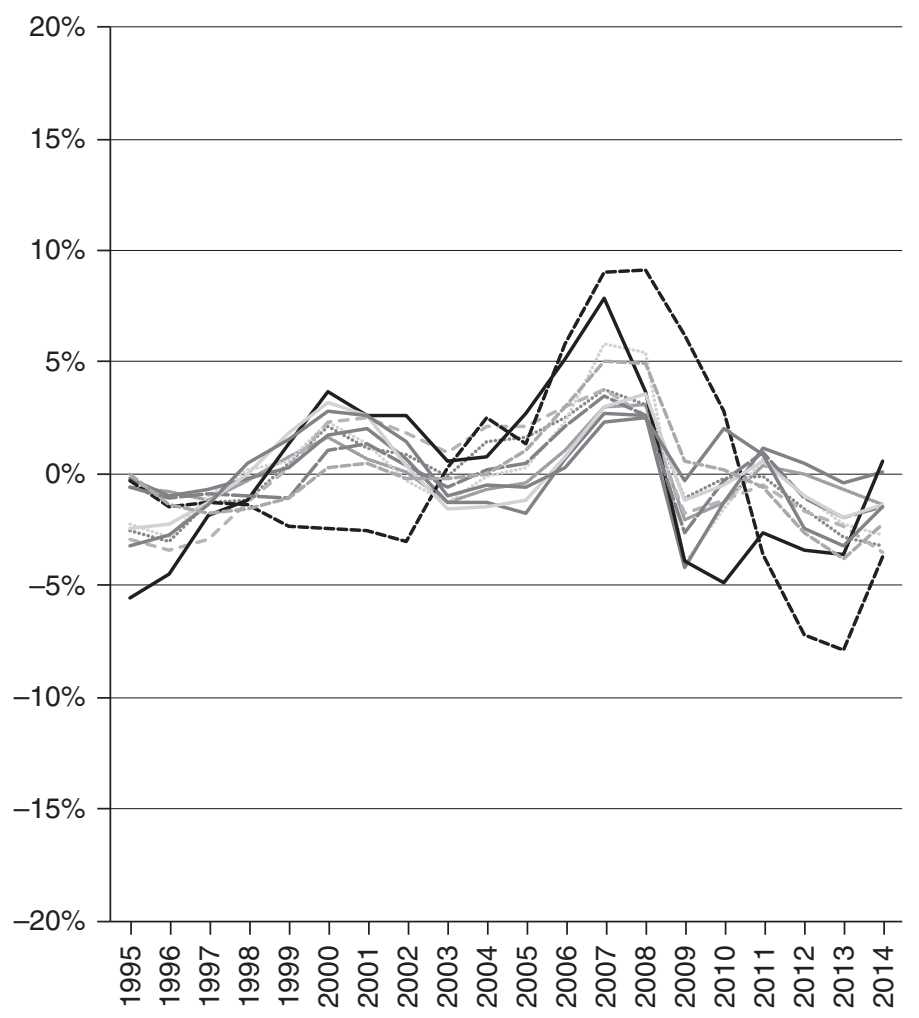

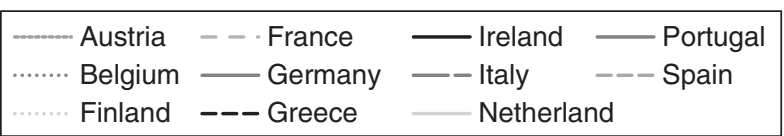

FIGURE 7.10: Business-cycle component of GDP growth, low lamda. Source: Own calculation based on Eurostat. 


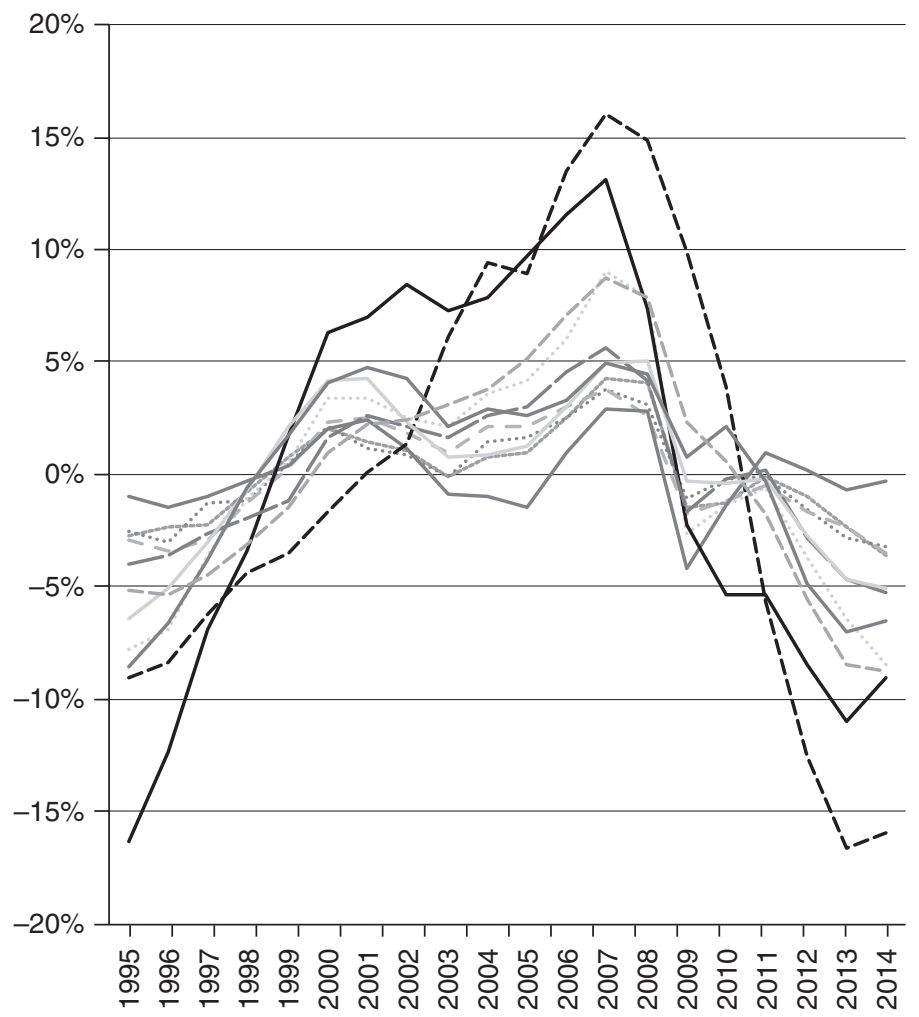

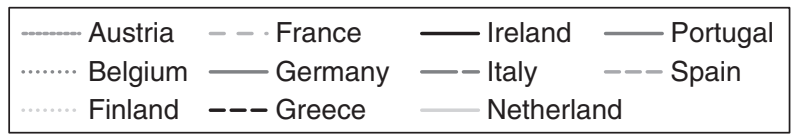

FIGURE 7.11: Business-cycle component of GDP growth, high lamda.

Source: Own calculation based on Eurostat (Figure 7.8).

TABLE 7.5: Correlation coefficients of cyclical components of GDP growth, low lamda

\begin{tabular}{lcccccccccc}
\hline \hline & Aus & Bel & Fin & Fra & Ger & Gre & Ire & Ita & Net & Por \\
\hline Austria & & & & & & & & & & \\
Belgium & 0.9 & & & & & & & & & \\
Finland & 0.9 & 0.9 & & & & & & & & \\
France & 0.9 & 0.9 & 0.9 & & & & & & & \\
Germany & 0.8 & 0.7 & 0.7 & 0.8 & & & & & & \\
Greece & 0.3 & 0.4 & 0.5 & 0.2 & -0.0 & & & & & \\
Ireland & 0.7 & 0.7 & 0.7 & 0.8 & 0.5 & 0.4 & & & & \\
Italy & 0.8 & 0.8 & 0.9 & 0.9 & 0.7 & 0.5 & 0.7 & & & \\
Netherlands & 0.8 & 0.8 & 0.8 & 0.7 & 0.7 & 0.3 & 0.6 & 0.7 & & \\
Portugal & 0.9 & 0.7 & 0.6 & 0.5 & 0.5 & 0.4 & 0.5 & 0.6 & 0.8 & \\
Spain & 0.6 & 0.7 & 0.7 & 0.6 & 0.3 & 0.9 & 0.7 & 0.8 & 0.6 & 0.6 \\
\hline
\end{tabular}

Source: Own calculations based on Eurostat. 


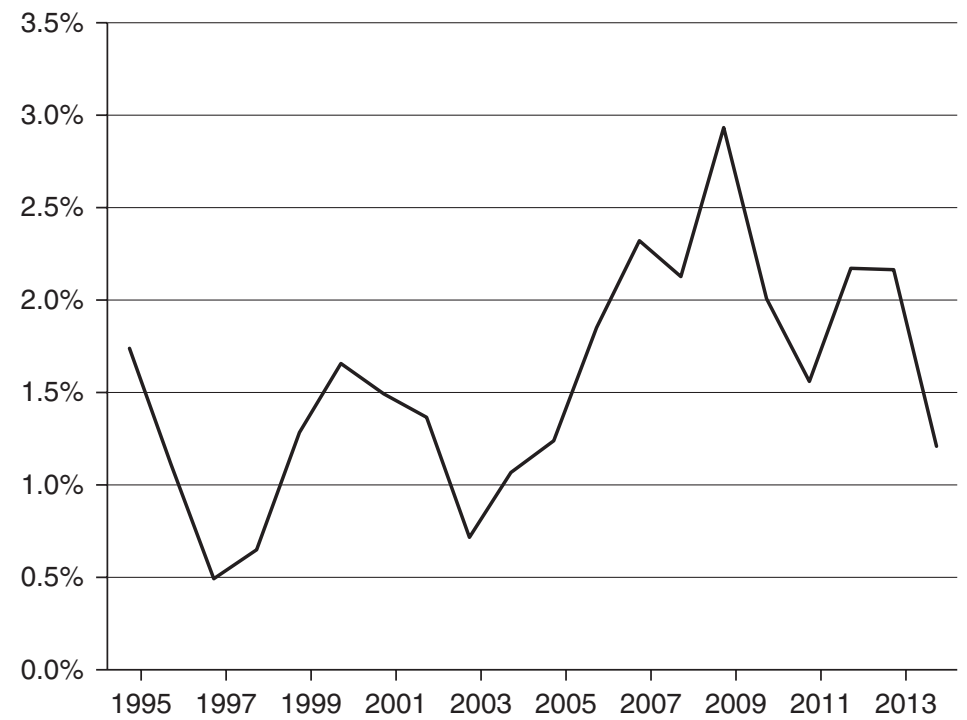

FIGURE 7.12: Standard deviation cyclical component, low lamda.

TABLE 7.6: Estimates of long-term growth in 1995 and 2014

\begin{tabular}{lccclccc}
\hline \hline Low lamda & \multicolumn{7}{c}{ High lamda } \\
\hline & Tre & Tre & Cha & & Tre & Treo14 & Cha \\
\hline Austria & 2.58 & 1.02 & -1.56 & Austria & 2.0 & 1.6 & -0. \\
Belgium & 2.49 & 0.90 & -1.59 & Belgium & 1.9 & 1.5 & -0. \\
Finland & 4.20 & 0.09 & -4.11 & Finland & 2.7 & 1.6 & -1. \\
France & 2.53 & 0.69 & -1.84 & France & 1.8 & 1.3 & -0. \\
Germany & 1.55 & 1.11 & -0.43 & Germany & 1.3 & 1.2 & -0. \\
Greece & 4.12 & -3.37 & -7.49 & Greece & 2.1 & 0.1 & -2. \\
Ireland & 7.66 & 0.41 & -7.26 & Ireland & 4.7 & 2.7 & -2. \\
Italy & 1.71 & -0.86 & -2.57 & Italy & 0.8 & 0.1 & -0. \\
Netherlands & 3.27 & 0.45 & -2.83 & Netherlands & 2.1 & 1.4 & -0. \\
Portugal & 2.98 & -0.87 & -3.85 & Portugal & 1.5 & 0.4 & -1. \\
Spain & 3.99 & -0.14 & -4.13 & Spain & 2.8 & 1.6 & -1. \\
\hline
\end{tabular}

Source: De Grauwe and Ji, ng above. 